\title{
The effect of Zingiber zerumbet rhizome ethanolic extract on sexual behaviours and sperm parameters in high fat diet-induced obese rats
}

\author{
Nurul Husna Md Jani ${ }^{1,2}$, Dzulsuhaimi Daud ${ }^{1,2^{*}}$, Nursirhan Athirah Sharkawi², Nooraain Hashim², Nur Hilwani Ismail², \\ Azani Salleh², Harita Hashim ${ }^{2}$ \\ ${ }^{1}$ Faculty of Applied Sciences, Universiti Teknologi MARA, Perak Branch, Tapah Campus, Tapah Road, 35400 Perak, Malaysia. \\ ${ }^{2}$ Faculty of Applied Sciences, Universiti Teknologi MARA, 40450 Shah Alam, Selangor, Malaysia.
}

\begin{tabular}{l}
\hline ARTICLE INFO \\
\hline Received on: $22 / 09 / 2020$ \\
Accepted on: $18 / 02 / 2021$ \\
Available online: $05 / 05 / 2021$
\end{tabular}

Key words:

Zingiber zerumbet, high

fat diet, obesity, sexual

behaviours, sperm

parameters.

\begin{abstract}
Obesity is a worldwide health problem that may impose infertility risk in males. This study was conducted to determine the effect of Zingiber zerumbet rhizome ethanolic extract (ZZREE) on sexual behaviours and sperm parameters in diet-induced obese rats. Male Sprague Dawley rats were fed with high fat diet (HFD), ad libitum daily for 6 weeks to induce obesity. Twenty obese rats were randomly divided into four groups $(n=6)$. A group of obese rats $(n=6)$ was treated orally with $1 \% \mathrm{~b}$. wt. (bodyweight) of saline and served as a negative control. The other three groups of obese rats were treated orally with 200,300 , and $400 \mathrm{mg} / \mathrm{kg}$ b. wt. of ZZREE, respectively. In addition, a group of non-obese rats $(n=6)$ was treated with $1 \% \mathrm{~b}$. wt. of saline and served as a normal control. All treatments were given once daily for 6 weeks. Upon completion of the treatments, sexual behaviours of male rats were observed. Then, all rats were sacrificed and epididymides were collected for sperm parameters analyses. Intromission latency, mount frequency (MF), and intromission frequency were improved significantly $(p<0.05)$ in obese rats treated with ZZREE $(200,300$, and $400 \mathrm{mg} / \mathrm{kg} \mathrm{b}$. wt.) compared to the negative control group. Sperm count, sperm motility, and the percentage of sperm with normal morphology were increased significantly $(p<0.05)$ in obese rats treated with ZZREE $(200,300$, and $400 \mathrm{mg} / \mathrm{kg}$ b. wt.) compared to the negative control. Therefore, it can be concluded that ZZREE exhibited positive effects in improving libido and sperm quality of HFD-induced obese rats. Further study is suggested to elucidate the mechanism involved.
\end{abstract}

\section{INTRODUCTION}

Obesity is characterised by an excessive fat deposition in adipose tissue and body weight elevation in an organism (Alarcon-Aguilar et al., 2007). According to the World Health Organisation (WHO), overweight or obesity is defined as an excessive or abnormal fat accumulation that may impair health conditions. The obesity epidemic affects millions of people in the modern world and induce all symptoms of metabolic syndromes which are associated with many additional health problems including asthma, atherosclerosis, non-alcoholic fatty

\section{*Corresponding Author}

Dzulsuhaimi Daud, Faculty of Applied Sciences, Universiti Teknologi MARA, Perak Branch, Perak, Malaysia; Faculty of Applied Sciences, Universiti Teknologi MARA, Shah Alam, Selangor, Malaysia. E-mail:dzuls990@uitm.edu.my liver, insulin resistance, and hypertension (Chien et al., 2016). Obesity contributes to the rise of fasting blood glucose level that leads to type 2 diabetes, leading to the increase in morbidity and mortality rates (Buysschaert et al., 2016). There are many factors that can contribute to obesity. It may be associated with a combination of sedentary lifestyle and an unhealthy diet (Oyeyipo et al., 2015). For instance, lack of exercise has shown to be a significant factor influencing the inflammatory cytokines associated with the state of obesity. Matos et al. (2005) documented that the obesity is highly related to nutritional factors that include the type and amount of carbohydrates, proteins, and fats contained in the diet. Excessive food intake that exceeds energy expenditure causes the retained energy to be deposited as fat (Rotimi et al., 2012).

Previously, many papers described the association in between obesity and male fertility. According to Wagner et al. (2016), the current trend in the declining of male fertility is in 
parallel with the increasing prevalence of obesity worldwide. Hammoud et al. (2008) concluded that male obesity negatively affects the endocrine system, resulting in hypogonadism and fluctuation in the level of oestrogen. Low level of testosterone in obese male is a clear sign of attenuated fertility (Tzeng et al., 2014). In obese males, a large amount of fat is deposited in the scrotum, which leads to oxidative stress, lipid peroxidation as well as amino acids, and carbohydrate oxidisation. Scrotal adiposity also has been associated with sperm DNA damage, resulting from an elevated temperature within the scrotum (Oyeyipo et al., 2015).

Direct relation in between male infertility and obesity encourages obese individual to prescribe weight-loss medication in order to reduce fat deposition, thus improving fertility. Orlistat, for example, has been clinically used worldwide due to its ability in reducing the dietary fat absorption in the gastrointestinal tract (Daneschvar et al., 2016). This drug inhibits the hydrolysis of free fatty acid and triglycerides. However, long term consumption of orlistat has been proven to cause undesirable side effects such as diarrhoea, bloating, flatulence, dyspepsia, and abdominal pain (Nakai et al., 2014). Close medical monitoring is needed while taking weight-loss medication, as it is well known for its negative effects. Hence, natural extracts from medical plants are preferable as it is not only effective, but are also relatively safe for consumption (Wu et al., 2013).

In recent years, the use of plant-based natural products to maintain health and prevent diseases increased dramatically, replacing synthetic drugs as it has a promising long-term safety record. Previous studies documented that Zingiber zerumbet has shown to possess a number of biological activities including antimicrobial, anti-inflammatory, anti-pyretic, anti-cancer, and antioxidant (Yob et al., 2011). Zingiber zerumbet, locally known as "lempoyang" in Malaysia, is a wild ginger belonging to the tropical and subtropical family of Zingiberaceae with a leafy stem growing up to $1.2 \mathrm{~m}(3.9 \mathrm{ft})$ tall. Despite its regular use as a food flavouring substance and appetiser, $Z$. zerumbet rhizome has been traditionally used for treating colds, ulcers, nausea, menstrual discomfort, and headache (Hong et al., 2016).

However, the potential of $Z$. zerumbet in improving fertility in obese male has been over looked. Previous study demonstrated that $Z$. zerumbet rhizome ethanolic extract (ZZREE) exhibits anti-hyperlipidaemia properties in rats fed with a high fat diet (HFD) and a reduction in hepatic lipid in HFD-induced obese hamster (Chang et al., 2012, 2014). According to Chang et al. (2012), kaempferol isolated from ethanolic extract of $Z$. zerumbet rhizome play a principle role in lipid modulation. Apart from that, the active component of $Z$. zerumbet rhizome, zerumbone has shown to improve lipid peroxidation (Tzeng et al., 2014). Therefore, this study was conducted to investigate the potential of $Z$. zerumbet in improving libido and fertility of obese males.

\section{MATERIALS AND METHODS}

\section{Plant materials and ethanolic extraction}

Fresh rhizomes of $Z$. zerumbet were harvested in February 2017 during rainy and humid weather from Sendayan Agriculture Centre, Negeri Sembilan Department of Agriculture, Malaysia. Plant was identified by Dr Mohd Firdaus Ismail from Institute of Bioscience Herbarium, Universiti Putra Malaysia (SK
3145/17). The rhizomes (5 kg) were washed, thin-sliced, dried, and pulverized with an electrical grinder (Panasonic MX-337, Malaysia) into coarse powder. Pulverized Z. zerumbet rhizomes were soaked in $80 \%$ ethanol in a ratio of $1: 5$, and allowed to stand at room temperature for a week with occasionally shaking. The extract was then evaporated to dryness under reduced pressure using rotary evaporator (BUCHI Rotavapor R-210, Switzerland) for the total elimination of alcohol followed by lyophilisation using freeze dryer (CHRIST Alpha 1-4 LD Plus, Germany) to yield residues $\left(437 \mathrm{~g}\right.$ ) and was kept in airtight container at $-20^{\circ} \mathrm{C}$ until further use (Hong et al., 2016).

\section{Experimental animals and acclimatization}

The experiment was conducted using 30 males and 12 females of Sprague Dawley rats purchased from A-Sapphire Enterprise Sdn Bhd (Kuala Lumpur, Malaysia) with the body weight range in between 200 and $250 \mathrm{~g}$ and age of 4-5 weeks. Experimental procedures and animal maintenance were conducted in accordance to UiTM Committee on the Ethical Use of Animal regulation (UiTM CARE 170/2017). All rats were housed in polypropylene cages with standard laboratory conditions, controlled temperature $\left(25^{\circ} \mathrm{C} \pm 3^{\circ} \mathrm{C}\right)$, and 12 -hour light-dark cycle. The rats were fed with standard rat pellets diet (partly consists of $3 \%$ fat, $50 \%$ carbohydrate, $21 \%$ protein, $5 \%$ fibre, $1.2 \%$ minerals) and water ad-libitum during 7 days of acclimatization prior to the experiments (Nur-Hilwani et al., 2014).

\section{Obesity induction}

Twenty male rats were given HFD and water ad libitum for 6 weeks in order to induce obesity. HFD contained, partly, $31.1 \%$ fat, $40.5 \%$ carbohydrate, $16.1 \%$ protein, $2.5 \%$ fibre, and $1.2 \%$ minerals (Ishak et al., 2013). Water for all animals were given ad libitum. The bodyweight and the length of all rats were taken on a weekly basis to measure the Lee's Index (Novelli et al., 2007).

\section{Lee's index $=\sqrt[3]{ }($ body weight $) /($ naso-anal length $)$}

The naso-anal length is the length in between the tips of the nose to the midpoint of anus of the rat. The Lee's index value of 0.3 and above indicates obesity state.

\section{Experimental design}

Thirty male rats were divided into five groups with six animals each. Group 1 was non-obese rats $(n=6)$ fed with standard rat pellets ad libitum, treated orally with saline (1\% of b. wt.) and served as a normal control group. Group 2 was obese rats $(n=6)$ fed with HFD ad libitum, treated orally with saline (1\% of b. wt.) and served as a negative control group. Group 3, 4 , and 5 were obese rats $(n=6)$ fed with HFD, treated with 200, 300 , and $400 \mathrm{mg} / \mathrm{kg}$ of b. wt. ZZREE, respectively. All treatments were conducted on a daily basis for 6 weeks (Chang et al., 2014).

\section{Sexual behaviour observation}

At the end of the ZZREE treatments, sexual behaviours of all male rats were observed as previously described by Agmo (1997). At the beginning of the experiment, the male rat was placed in the test arena $(40 \times 60 \times 40 \mathrm{~cm}$ high $)$ for 5 minutes (acclimatization). After 5 minutes, a female rat was dropped 
silently from one side of the test arena as a stimulus (Lucio et al., 2013). The sexual behaviour test was conducted during the dark phase under dim white light in a sound-proof room, away from other rats. A video camera was placed on top of the box for video recordings. The ratio of male to female rats was 1:1 with 5 minutes observation per session. The parameters that were observed during the test were; the mount latency (ML), intromission latency (IL), mount frequency (MF), and intromission frequency (IF) (Table 1).

\section{Sperm collection and sperm analyses}

Upon completion of the sexual behaviours test, all animals were euthanized by overdosed of diethyl ether. The epididymis was collected and the sperm was obtained by macerating the cauda epididymis with a surgical blade and minced in a $35 \mathrm{~mm}$ plastic petri dish containing $2 \mathrm{ml}$ of Dulbecco's Modified Eagle's Medium (Sigma-Aldrich, St. Louis, MO) supplemented with 3 $\mathrm{mg} / \mathrm{ml}$ bovine serum albumin (Sigma-Aldrich, St. Louis, MO). Sperm suspension was incubated in $\mathrm{CO}_{2}$ incubator $\left(5 \% \mathrm{CO}_{2}\right.$, $37^{\circ} \mathrm{C}$ ) for 30 minutes to allow the sperm to swim-up. Then, sperm analyses (sperm motility, sperm count, and sperm morphology) were carried out as previously outlined by the World Health Organization (2010).

The sperm motility was examined immediately 30 minutes after the sperm was incubated in $\mathrm{CO}_{2}$ incubator. A volume of $10 \mu \mathrm{l}$ of sperm suspension was placed on the grid of a Makler Chamber (Sefi Medical Instruments, Hicksville, NY) using a micropipette. The sample was allowed to stand for 1 minute to prevent fluid-drift, then was observed under the light microscope at $100 \times$ of total magnification (Leica Biosystem, Germany). The motility of the sperm was graded as progressive (PR), non-progressive (NP), and non-motile (NM). In total, three replications of 200 sperm per replication were observed (World Health Organization, 2010).

Sperm count was assessed using a Makler Chamber (Sefi Medical Instruments, Hicksville, NY). A volume of $10 \mu \mathrm{l}$ of sperm suspension was placed on the grid of the Makler Chamber. Ten grids on the Makler Chamber were chosen randomly and the number of sperm on the selected grids were counted. The number of sperm in 10 grids were expressed as a sperm concentration in millions $/ \mathrm{ml}$.

For sperm morphology determination, $300 \mu \mathrm{l}$ of sperm suspension was diluted with $900 \mu \mathrm{l}$ of $10 \%$ formalin (Merrells et al., 2009). Then, a drop of eosin was added and mixed gently. After 5 minutes, a smear was made by placing a drop of mixture on a glass slide and allowed to air-dry. The morphology of normal and abnormal sperm was examined under a light microscope (400× of total magnification). A minimum of five microscopic fields were assessed for each slide and 200 sperm were observed

Table 1. Sexual behaviour parameters.

\begin{tabular}{cl}
\hline Parameter & Description \\
\hline ML & Time from the introduction of female until the first mount \\
IL & Time from the introduction of the female until the first intromission \\
MF & The number of mount per series \\
IF & The number of intromission per series \\
\hline
\end{tabular}

Adapted from Agmo (1997). to evaluate sperm morphology, in order to achieve an acceptably low sample error. The sperm morphology was divided into two classifications which are normal and abnormal. The abnormal sperm were distinguished by missing a head, flattened hook or pinhead and bent or coiled tail (World Health Organization, 2010).

\section{Statistical analysis}

All data are expressed as mean \pm standard error of mean (SEM) and were analysed using one-way analysis of variance followed by Duncan methods for post-hoc analysis by IBM Statistical Package for the Social Sciences software version 24.00. $p$-value of $<0.05$ was considered as statistically significant.

\section{Results and Discussion}

\section{Effects of ZZREE on sexual behaviours}

ML was not improved $(p>0.05)$ in HFD-induced obese rats treated with various dosages of ZZREE compared to the negative control rats (HFD-induced obese rats treated with saline). IL decreased significantly $(p<0.05)$ in HFD-induced obese rats treated with ZZREE 200 (54.55 \pm 2.98 seconds), ZZREE 300 (56.15 \pm 3.39 seconds), and ZZREE 400 (63.93 \pm 4.47 seconds) when compared to the negative control rats $(261.55$ \pm 0.65 seconds). Mount frequency (MF) increased significantly ( $p$ $<0.05)$ in HFD-induced obese rat treated with ZZREE $200(2.43$ \pm 0.51 seconds), ZZREE 300 (2.51 \pm 0.25 seconds $)$ and ZZREE $400(2.49 \pm 0.43$ seconds $)$ compared to the negative control rats $(1.47 \pm 0.23$ seconds). IF increased significantly $(p<0.05)$ in HFD-induced obese rats treated with ZZREE $200(2.01 \pm 0.47$ seconds), ZZREE 300 (1.94 \pm 0.39 seconds) dan ZZREE 400 $(1.55 \pm 0.32$ seconds) compared to the negative control rats $(0.89$ \pm 0.57 seconds) (Table 2).

The presence of kaemferol in the rhizome of $Z$. zerumbet as reported by Yob et al. (2011) may be contributed to the improvement of libido or the changes in sexual behaviours of obese rats. The basis for this suggestion is drawn from the sexual copulatory enhancing properties of kaemferol isolated from Ginkgo biloba extract (Enema et al., 2018). Besides that, the testosterone increment in rats treated with ZZREE (Md-Jani et al., 2018) may have also played a role in enhancing sexual behaviours of obese male rats as androgens are known to influence sexual behaviour and erection in male (Al-Hameed and Heshmat, 2019). Thus, the present study reveal for the first time a potent aphrodisiac effect of $Z$. zerumbet.

Table 2. The effect of ZZREE on sexual behaviour parameters of HFD-induced obese rats $(n=6)$.

\begin{tabular}{lcccc}
\hline Group & ML (s) & IL (s) & MF (s) & IF (s) \\
\hline G1: Normal control & $16.58 \pm 0.43^{\mathrm{a}}$ & $17.25 \pm 0.42^{\mathrm{a}}$ & $3.59 \pm 0.97^{\mathrm{a}}$ & $2.55 \pm 0.73^{\mathrm{a}}$ \\
G2: Negative control & $58.42 \pm 1.18^{\mathrm{b}}$ & $261.55 \pm 0.65^{\mathrm{b}}$ & $1.47 \pm 0.23^{\mathrm{b}}$ & $0.89 \pm 0.57^{\mathrm{b}}$ \\
G3: ZZREE 200 & $53.32 \pm 5.53^{\mathrm{b}}$ & $54.55 \pm 2.98^{\mathrm{c}}$ & $2.43 \pm 0.51^{\mathrm{c}}$ & $2.01 \pm 0.47^{\mathrm{c}}$ \\
G4: ZZREE 300 & $54.83 \pm 7.12^{\mathrm{b}}$ & $56.15 \pm 3.39^{\mathrm{c}}$ & $2.51 \pm 0.25^{\mathrm{c}}$ & $1.94 \pm 0.39^{\mathrm{c}}$ \\
G5: ZZREE 400 & $59.28 \pm 4.83^{\mathrm{b}}$ & $63.93 \pm 4.47^{\mathrm{c}}$ & $2.49 \pm 0.43^{\mathrm{c}}$ & $1.55 \pm 0.32^{\mathrm{c}}$ \\
\hline
\end{tabular}

Values are presented as means \pm SEM.

Values with different superscript within the same column shows a significant difference at $p<0.05$.

$\mathrm{HFD}=$ high fat diet; $\mathrm{ML}=$ mount latency; $\mathrm{IL}=$ intromission latency; $\mathrm{MF}=$ Mount frequency; IF = Intromission frequency. 
Table 3. The effect of ZZREE on sperm parameters of HFD-induced obese rats $(n=6)$.

\begin{tabular}{lccccc}
\hline \multirow{2}{*}{ Group } & $\begin{array}{l}\text { Sperm count } \\
\left(\text { sperm } \times \mathbf{1 0}^{\mathrm{G}}\right)\end{array}$ & \multicolumn{3}{c}{ Sperm motility (\%) } & \multirow{2}{*}{ Normal sperm (\%) } \\
\cline { 3 - 5 } & $35.00 \pm 5.53^{\mathrm{a}}$ & $54.25 \pm 2.06^{\mathrm{a}}$ & $20.50 \pm 3.01^{\mathrm{a}}$ & $25.25 \pm 2.53^{\mathrm{a}}$ & $83.10 \pm 1.70^{\mathrm{a}}$ \\
\hline G1: Normal control & $32.33 \pm 5.43^{\mathrm{a}}$ & $32.50 \pm 9.30^{\mathrm{b}}$ & $9.25 \pm 3.64^{\mathrm{b}}$ & $58.00 \pm 12.43^{\mathrm{b}}$ & $69.40 \pm 2.57^{\mathrm{b}}$ \\
G2: Negative control & $55.87 \pm 4.86^{\mathrm{c}}$ & $55.25 \pm 2.75^{\mathrm{a}}$ & $19.00 \pm 5.12^{\mathrm{a}}$ & $25.75 \pm 4.41^{\mathrm{a}}$ & $87.50 \pm 1.04^{\mathrm{a}}$ \\
G3: ZZREE 200 & $56.27 \pm 4.55^{\mathrm{c}}$ & $62.50 \pm 1.76^{\mathrm{c}}$ & $17.25 \pm 1.75^{\mathrm{a}}$ & $20.25 \pm 3.43^{\mathrm{a}}$ & $89.10 \pm 1.32^{\mathrm{a}}$ \\
G4: ZZREE 300 & $54.80 \pm 5.18^{\mathrm{c}}$ & $63.50 \pm 2.84^{\mathrm{c}}$ & $13.75 \pm 2.84^{\mathrm{c}}$ & $22.25 \pm 3.01^{\mathrm{a}}$ & $89.20 \pm 0.83^{\mathrm{a}}$ \\
\hline G5: ZZREE 400 & & & & & NP
\end{tabular}

Values are presented as means $\pm \mathrm{SEM}$.

Values with different superscript within the same column shows a significant difference at $p<0.05$ $\mathrm{HFD}=$ high fat diet; $\mathrm{PR}=$ progressive motility; $\mathrm{NP}=$ non-progressive motility; $\mathrm{NM}=$ non-motile .

\section{Effect of ZZREE on sperm count}

Sperm count decreased but not statistically significant $(p$ $>0.05)$ in negative control rats (HFD-induced obese rats treated with saline) $\left(32.22 \pm 5.43 \times 10^{6} \mathrm{sperm} / \mathrm{ml}\right)$ compared to normal control rats $\left(35.00 \pm 5.53 \times 10^{6} \mathrm{sperm} / \mathrm{ml}\right)$. However, ZZREE 200, ZZREE 300, and ZZREE 400 significantly increased $(p<0.05)$ the sperm count of HFD-induced obese rats, compared to the negative control rats (Table 3 ). The highest sperm count was recorded by HFD-induced obese rats treated with ZZREE $300(56.27 \pm 4.55 \times$ $\left.10^{6} \mathrm{sperm} / \mathrm{ml}\right)$ followed by ZZREE $200\left(55.87 \pm 4.86 \times 10^{6} \mathrm{sperm} /\right.$ $\mathrm{ml})$ and ZZREE $400\left(54.80 \pm 5.18 \times 10^{6} \mathrm{sperm} / \mathrm{ml}\right)$. However, there was no significant different $(p>0.05)$ in sperm count among the ZZREE treated obese rats.

A large amount of adipose tissue was accumulated in the testis of obese rats, and this had probably induced the generation of oxidative stress. Oxidative stress will disrupt the Leydig cell's activity and may affect spermatogenesis, hence, causing a low sperm concentration (Vigueras-Villasenor et al., 2011). The increment in sperm count observed in ZZREE treated obese rats may be due to the antioxidant properties of ZZREE, especially antioxidant known as zerumbone (Nag et al., 2013). The majority of the studies confirmed the beneficial effect of antioxidant on sperm count (Affonso et al., 2017; Dang et al., 2017). Previously, AlHameed and Heshmat (2019) reported an improvement in sperm count of male rabbits supplemented with the rhizome of closely related genera in the family Zingiberaceae, Zingiber officinale. Hence, the ability of ZZREE in increasing the concentration of sperm may due to the mutual bioactive compounds contained between both species.

\section{Effect of ZZREE on sperm motility}

Sperm progressive motility (PR) decreased significantly $(p<0.05)$ in negative control rats (HFD-induced obese rats treated with saline) $(32.5 \% \pm 9.3 \%)$ compared to the normal control rats $(54.25 \% \pm 2.06 \%)$. The percentage of sperm with PR motility increased significantly $(p<0.05)$ in HFD-induced obese rats treated with various dosages of ZZREE compared to negative control rats (Table 3). Obese male rats treated with ZZREE 400 showed the highest percentage value of PR motile sperm $(63.5 \%$ $\pm 2.84 \%)$ followed by obese rats treated with ZZREE $300(62.5 \%$ $\pm 1.76 \%)$ and ZZREE $200(55.25 \% \pm 2.75 \%)$. However, the percentage of sperm with PR motility did not differ significantly among HFD-induced obese rats treated with ZZREE 200, ZZREE 300, and ZZREE 400.
The decreased in the sperm motility of negative control rats (HFD-induced obese rats treated with saline) were in line with the study by Borges et al. (2017) who demonstrated a reduction in sperm motility of HFD-induced obese mice compared to lean mice. Due to the large quantities of polyunsaturated fatty acids in their plasma membrane and low concentration of scavenging enzyme, spermatozoa are particularly susceptible to oxidative stress (Bakos et al., 2011). Gujjala et al. (2016) reported that the oxidative stress generated in obese rats resulted in lipid peroxidation of mitochondrial membrane with impairment in sperm motility, thus decreased the male fertility (Jensen et al., 2004). The improvement in PR motility of ZZREE treated HFDinduced obese rats demonstrated that ZZREE may have an action to confer protection in preserving the sperm and maintaining sperm motility in obese male. Previous investigator documented that ZZREE is rich with zerumbone (Nag et al., 2013), a good anti-oxidant agent (Tzeng et al., 2014). It was demonstrated that the anti-oxidant is necessary for maintaining and stabilising the sperm mitochondrial function (Dang et al., 2017). Anti-oxidant also plays a role in the activation of calcium ion $\left(\mathrm{Ca}^{2+}\right)$ channels in the sperm flagellum, thus, increase sperm motility (NowickaBauer and Nixon, 2020).

\section{Effect of ZZREE on sperm morphology}

Finding from the current studies showed that the percentage of sperm with normal morphology was decreased significantly $(p<0.05)$ in negative control (HFD-induced rats treated with saline) $(69.4 \% \pm 2.57 \%)$ compared to normal control rats $(83.1 \% \pm 1.7 \%)$. When HFD-induced obese rats were treated with ZZREE, the percentages of sperm with normal morphology were increased significantly $(p<0.05)$. However, the percentage of sperm with normal morphology did not differ significantly $(p>$ $0.05)$ among HFD-induced obese rats treated with low $(200 \mathrm{mg} / \mathrm{kg}$ of bwt), medium (300 mg/kg of bwt), and high ( $400 \mathrm{mg} / \mathrm{kg}$ of bwt) dosages of ZZREE. HFD-induced obese rats treated with ZZREE 400 showed the highest percentage of normal sperm $(89.2 \% \pm$ $0.83 \%)$, followed by ZZREE $300(89.1 \% \pm 1.32 \%)$ and ZZREE $200(87.5 \% \pm 1.04 \%)$ as presented in Table 3.

In this study which used animal models to resemble obese male had found an impact of obesity on sperm morphology, and in line with previous studies (Borges et al., 2017). The reduction of percentage of sperm with normal morphology of untreated obese rats (negative control group) in the current study had strengthen the postulation that obesity is able to cause damage in sperm cells, 
in particular altering the physical and molecular structure of germ cell (Palmer et al., 2012). Zerumbone, an anti-oxidant may lead to improving the percentage of sperm with normal morphology in HFD-induced obese rats. Majority of reviewed studies showed significant positive association in between anti-oxidant with sperm parameters including the percentage of sperm with normal morphology (Ahmadi et al., 2016).

\section{CONCLUSION}

As a conclusion, ZZREE administration improved the sexual desire and sperm parameters (sperm count, motility, and percentage of sperm with normal morphology) in HFD-induced obese rats. These findings may suggest that ZZREE could aid in male fertility by improving male reproductive functions. Thus, ZZREE supplementation may be useful in enhancing fertility in obese males. However, more experimental investigations should be carried out to sanction this hypothesis.

\section{ACKNOWLEDGMENTS}

This work was financially supported by the Institute of Research Management and Innovation (IRMI), Universiti Teknologi MARA, Malaysia (600-IRMI/DANA 5/3 LESTARI 0088/2016). Authors would like to acknowledge Research Management Centre (RMC), Universiti Teknologi MARA for administrative support.

\section{CONFLICT OF INTEREST}

The authors declare that there is no conflict of interest toward the publication of this article.

\section{AUTHOR CONTRIBUTIONS}

All authors made substantial contributions to conception and design, acquisition of data, or analysis and interpretation of data; took part in drafting the article or revising it critically for important intellectual content; agreed to submit to the current journal; gave final approval of the version to be published; and agree to be accountable for all aspects of the work. All the authors are eligible to be an author as per the international committee of medical journal editors (ICMJE) requirements/guidelines.

\section{ETHICAL APPROVALS}

Experimental procedures and animal maintenance were conducted in accordance to UiTM Committee on the Ethical Use of Animal regulation (approval number: UiTM CARE 170/2017).

\section{PUBLISHER'S NOTE}

This journal remains neutral with regard to jurisdictional claims in published institutional affiliation.

\section{REFERENCES}

Affonso FJ, Carvalho HF, Lançoni R, Lemes KM, Leite TG, Oliveira LZ, Arruda RP. Addition of antioxidants myoinositol, ferulic acid, and melatonin and their effects on sperm motility, membrane integrity, and reactive oxygen species production in cooled equine semen. J Equine Vet Sci, 2017; 59:57-63.

1:203-9.

Agmo A. Male rat sexual behavior. Brain Res Protoc, 1997;

Ahmadi S, Bashiri R, Ghadiri-Anari A, Nadjarzadeh A. Antioxidant supplements and semen parameters: an evidence based review. Int J Reprod Biomed (Yazd), 2016; 14:729-36.
Alarcon-Aguilar FJ, Zamilpa A, Perez-Garcia MD, AlmanzaPerez JC, Romero-Nunez E, Campos-Sepulveda EA, Roman-Ramos R. Effect of Hibiscus sabdariffa on obesity in MSG mice. J Ethnopharmacol, 2007; 114:66-71.

Al-Hameed NEA, Heshmat HA. Effect of ginger aqueous extract on some reproductive and antioxidant parameters in male rabbits. Alex J Vet Sci, 2019; 60:38-45.

Bakos HW, Mitchell M, Setchell BP, Lane M. The effect of paternal diet-induced obesity on sperm function and fertilisation in a mouse model. Int J Androl, 2011; 34:402-10.

Borges BC, Garcia-Galiano D, Cruz-Machado SS, Han X, Gavrilina GB, Saunders TL, Auchus RJ, Hammoud SS, Smith GD, Elias $\mathrm{CF}$. Obesity-induced infertility in male mice is associated with disruption of Crisp4 expression and sperm fertilization capacity. Endocrinology, 2017; 158:2930-43.

Buysschaert B, Aydin S, Morelle J, Hermans M, Jadoul M, Demoulin N. Weight loss at a high cost: orlistat-induced late-onset severe kidney disease. Diabetes Metab, 2016; 42:62-4.

Chang CJ, Liou S, Tzeng T, Liu I. The ethanol extract of Zingiber zerumbet smith attenuates non-alcoholic fatty liver disease in hamsters fed on high-fat diet. Food Chem Toxicol, 2014; 65:33-42.

Chang CJ, Tzeng T, Liou S, Chang Y, Liu I. Regulation of lipid disorders by ethanol extracts from Zingiber zerumbet in high-fat dietinduced rats. Food Chem, 2012; 132:460-7.

Chien MY, Ku YH, Chang JM, Yang CM, Chen CH. Effects of herbal mixture extracts on obesity in rats fed a high-fat diet. J Food Drug Anal, 2016; 24:594-601

Daneschvar HL, Aronson MD, Smetana GW. FDA approved anti-obesity drugs in the United States. Am J Med, 2016; 129:879e1-e6.

Dang Y, Li Z, Luo B, Pan L, Wei Q, Zhang Y. Protective effects of apigenin against acrylonitrile-induced subchronic sperm injury in rats. Food Chem Toxicol, 2017; 109:517-25.

Enema OJ, Umoh UF, Umoh RA, Ekpo EG, Adesina SK, Eseyin OA. Chemistry and pharmacology of aphrodisiac plants: a review. J Chem Pharm Res, 2018; 10:70-98.

Gujjala S, Putakala M, Gangarapu V. Protective effect of Caralluma fimbriata against high-fat diet induced testicular oxidative stress in rats. Biomed Pharmacother, 2016; 83:167-76.

Hammoud AO, Gibson M, Peterson CM, Meikle AW, Carrel DT. Impact of male obesity on infertility: a critical review of the current literature. Fertil Steril, 2008; 90:897-904.

Hong T, Tzeng T, Liou S, Liu I. The ethanol extract of Zingiber zerumbet rhizomes mitigates vascular lesions in the diabetic retina. Vascul Pharmacol, 2016; 76:18-27.

Ishak NA, Ismail M, Hamid M, Ahmad Z, Ghafar SAA Antidiabetic and hypolipidemic activities of Curculigo latifolia fruit: root extract in high fat fed diet and low dose STZ induced diabetic rats. Evid Based Complementary Altern Med, 2013; 2013:601838; doi: $10.1155 / 2013 / 601838$

Jensen TK, Andersson AM, Jorgensen N, Andersen AG, Carlsen E, Petersen JH. Body mass index in relation to semen quality and reproductive hormones among 1,558 Danish men. Fertil Steril, 2004 82:863-70.

Lucio RA, Tlachi-López JL, Eguibar JR, Agmo A. Sperm count and sperm motility decrease in old rats. Physiol Behav, 2013; 110:73-9.

Matos SL, de Paula H, Pedrosa ML, dos Santos RC, de Oliveira EL, Júnior DAC, Silva ME. Dietary models for inducing hypercholesterolemia in rats. Braz Arch Biol Technol, 2005; 48:203-9.

Md-Jani NH, Daud D, Sharkawi N, Hashim H, Hilwani NH, Salleh A, Hashim N. The effect of Zingiber zerumbet rhizome ethanol extract (ZZREE) on testosterone level and testes histoarchitecture in high fat diet-induced obese rats. Malays Appl Biol, 2018; 47:181-7.

Merrells KJ, Blewett H, Jamieson JA, Taylor CG, Suh M. Relationship between abnormal sperm morphology induced by dietary zinc deficiency and lipid composition in testes of growing rats. Br J Nutr, 2009; 102:226-32. 
Nag A, Bandyopadhyay M, Mukherjee A. Antioxidant activities and cytotoxicity of Zingiber zerumbet (L.) Smith rhizome. J Pharmacogn Phytochem, 2013; 2:102-8.

Nakai K, Wada R, Iida S, Kawanishi T, Matsumoto Y. Modeling and simulation of orlistat to predict weight loss and weight maintenance in obesity patients. Drug Metab Pharmacokinet, 2014; 29:278-82.

Novelli EL, Diniz YS, Galhardi CM, Ebaid GM, Rodrigues HG, Mani F, Novelli Filho JL. Anthropometrical parameters and markers of obesity in rats. Lab Anim, 2007; 41:111-9.

Nowicka-Bauer K, Nixon B. Molecular changes induced by oxidative stress that impair human sperm motility. Antioxidants, 2020; 9:134-55.

Nur-Hilwani I, Nasibah R, Nurdiana S, Norashirene MJ. Gonadotoxic and cytotoxic effect of induced obesity via monosodium glutamate on Mus musculus testis cytoarchitecture and sperm parameter. Int J Bio Biomol Agric Food Biotechnol Eng, 2014; 8:1000-3.

Oyeyipo I, Maartens P, Du Plessis S. Diet-induced obesity alters kinematics of rat spermatozoa. Asian Pac J Reprod, 2015; 4:235-9.

Palmer NO, Bakos HW, Fullston T, Lane M. Impact of obesity on male fertility, sperm function and molecular composition. Spermatogenesis, 2012; 2:253-63.

Rotimi O, Olayiwola I, Ademuyiwa O, Balogun E. Effects of fibre-enriched diets on tissue lipid profiles of MSG obese rats. Food Chem Toxicol, 2012; 50:4062-7.

Tzeng T, Lu H, Liou S, Chang CJ, Liu I. Lipid-lowering effects of zerumbone, a natural cyclic sesquiterpene of Zingiber zerumbet smith, in high-fat diet-induced hyperlipidemic hamsters. Food Chem Toxicol, 2014; 69:132-9.
Vigueras-Villasenor RM, Rojas-Castañeda JC, Chávez-Saldara M, Gutierrez-Perez O, García-Cruz ME, Cuevas-Alpuche O, Zambrano E. Alterations in the spermatic function generated by obesity in rats. Acta Histochem, 2011; 113:214-20.

Wagner I, Klöting N, Atanassova N, Savchuk I, Sprote C, Kiess W, Svechnikov K. Prepubertal onset of obesity negatively impacts on testicular steroidogenesis in rats. Mol Cell Endocrinol, 2016; 437:154-62.

World Health Organization. WHO laboratory manual for the examination and processing of human semen. 5th edition, WHO Press, Geneva, Switzerland, 2010.

Wu X, Ernst F, Conkle JL, Gan J. Comparative uptake and translocation of pharmaceutical and personal care products (PPCPs) by common vegetables. Environ Int, 2013; 60:15-22.

Yob NJ, Jofrry SM, Affandi MM, The LK, Salleh MZ, Zakaria ZA. Zingiber zerumbet (L.) Smith: a review of its ethnomedicinal, chemical, and pharmacological uses. Evid Based Complement Altern Med, 2011; 2011:543216; doi:10.1155/2011/543216.

\section{How to cite this article:}

Jani NHM, Daud D, Sharkawi NA, Hashim N, Ismail NH, Salleh A, Hashim H. The effect of Zingiber zerumbet rhizome ethanolic extract on sexual behaviours and sperm parameters in high fat diet-induced obese rats. J Appl Pharm Sci, 2021; 11(05):079-084. 